\title{
The Mountaineer Site
}

A FOLSOM WINTER CAMP IN THE ROCKIES

Brian N. Andrews, David J. Meltzer, and Mark Stiger

W I T H C O N R I B U T I O N S B Y
Richard J. Anderson
Andrew R. Boehm
Christy E. Briles
Katherine A. Cross
Steven D. Emslie
Metin I. Eren
Richard F. Gunst
Kalanka P. Jayalath
Brooke M. Morgan
Cathy Whitlock

UNIVERSITY PRESS OF COLORADO

Louisville

\section{Copyrighted material Not for distribution}


(C) 202I by University Press of Colorado

Published by University Press of Colorado

245 Century Circle, Suite 202

Louisville, Colorado 80027

All rights reserved

Manufactured in the United States of America

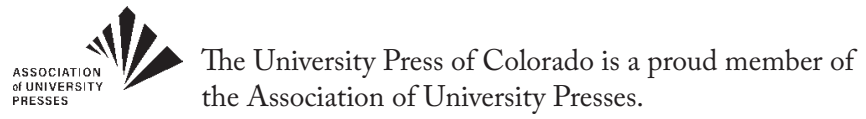

The University Press of Colorado is a cooperative publishing enterprise supported, in part, by Adams State University, Colorado State University, Fort Lewis College, Metropolitan State University of Denver, Regis University, University of Colorado, University of Northern Colorado, University of Wyoming, Utah State University, and Western Colorado University. $\infty$ This paper meets the requirements of the ANSI/NISO Z39.48-I992 (Permanence of Paper)

ISBN: 978-I-64642-I39-8 (hardcover)

ISBN: $978-\mathrm{I}-64642-\mathrm{I} 4 \mathrm{O}-4$ (ebook)

https://doi.org/Io.5876/978I64642I404

Library of Congress Cataloging-in-Publication Data

Names: Andrews, Brian N., author. | Meltzer, David J., author. | Stiger, Mark, author.

Title: The Mountaineer site : a Folsom winter camp in the Rockies / Brian N. Andrews,

David J. Meltzer, Mark Stiger.

Description: Louisville : University Press of Colorado, [202I] | Includes bibliographical references and index.

Identifiers: LCCN 202100II86 (print) | LCCN 2021001187 (ebook) | ISBN 9781646421398 (hardcover) | ISBN 978164642I404 (ebook)

Subjects: LCSH: Folsom culture-Colorado-Summit County-Antiquities. |

Excavations (Archaeology)—Colorado-Summit County. | Land settlement patterns, Prehistoric-Colorado-Summit County. | Human ecology—Colorado-Summit County. | Social archaeology-Colorado-Summit County.

Classification: LCC E99.F65 M68 202I (print) | LCC E99.F65 (ebook) | DDC 978.8/45-dc23

$\mathrm{LC}$ record available at https://lccn.loc.gov/202100II86

LC ebook record available at https://lccn.loc.gov/202100II87

The University Press of Colorado gratefully acknowledges the support of the Quest Archaeological Research Fund of Southern Methodist University toward the publication of this volume.

Cover photograph by Steven D. Emslie

\section{Copyrighted material Not for distribution}


I. Introduction

Brian N. Andrews, David J. Meltzer, and

Mark Stiger 3

2. Geology, Site Formation, and Geochronology

Brian N. Andrews, Mark Stiger,

Brooke M. Morgan, and Andrew R. Boehm

3. The Environmental Context

Brian N. Andrews, David J. Meltzer,

Steven D. Emslie, Christy E. Briles, and

Cathy Whitlock 50

4. Archaeological Research Design and Field Methods

Brian N. Andrews, David J. Meltzer, and

Mark Stiger 8I

5. Blocks $X$ and $Y$

Andrew R. Boehm and Richard J. Anderson

6. Spatial Characterization of the Large Rock

Patterns in Blocks $\mathrm{C}, \mathrm{X}$, and $\mathrm{Y}$

Kalanka P. Jayalath, Richard F. Gunst, and

David J. Meltzer

IIO

7. Block A

Mark Stiger $\quad$ I33 
8. Block B

Mark Stiger $\quad$ I74

9. Block C

Brooke M. Morgan, Brian N. Andrews, and David J. Meltzer $\quad 196$

Io. Block D

Brian N. Andrews 234

II. Block F

Mark Stiger $\quad 270$

I2. The Mountaineer Folsom Projectile Point Assemblage

David J. Meltzer and Metin I. Eren 296

I3. A Quantitative Test of Folsom Unifacial Tool Recycling in Block C Metin I. Eren, Katherine A. Cross, Brian N. Andrews, and David J. Meltzer 359

I4. The Mountaineer Faunal Remains

Andrew R. Boehm 368

15. The Mountaineer Site: Summary and Conclusions

David J. Meltzer, Brian N. Andrews, and Mark Stiger 394

Appendix: Field Procedures and Protocols 425

References 439

Index 485

Authors $\quad 497$ 
Over the last twenty-five years or so, it has become increasingly evident that hunter-gatherers across the North American West exploited and/or resided in high-altitude settings, which, following Aldenderfer (2006), we define as locations at elevations greater than 2,500 meters above sea level (e.g., Benedict r992a, 1992b, 2007; Bettinger 1991; Cannon et al. 2015; LaBelle and Cassells 20I2; Morgan et al. 20I2; Pitblado 20I6; Pitblado and Brunswig 2007; Stiger 2006; Stirn 2014; Thomas 2014). The question is no longer whether groups occupied the Rocky Mountains or the high mountains of the Great Basin, habitats long supposed to have been either avoided altogether or used briefly and perhaps only during times of stress elsewhere (e.g., Benedict and Olson 1978; Husted 1969, 1974; Kroeber 1939; Steward 1938). Rather, the issues now revolve around when those regions were first inhabited, how hunter-gatherers made use of these habitats and their resources, the adaptive (perhaps physiological ones) challenges these environments may have posed, and the duration and intensity of human occupation at different times (e.g., Andrews 20I0; Kornfeld 2013, 2015; Morgan 2015; Pitblado 2016; Surovell 2009).

Recent research in the Rocky Mountains has demonstrated that although there are a few occurrences of isolated Clovis-age material in the region, the earliest substantial and securely documented human presence was by Folsom groups (Andrews 2010; Frison 2004; Jodry I999b; Kornfeld 2015; Pitblado 2016; Pitblado
Introduction

Brian N. Andrews, David J. Meltzer, and Mark Stiger 
and Brunswig 2007; Stiger 2006). In fact, most reported Folsom sites in Colorado are in the southern Rocky Mountains and not the Great Plains portion of the state. Folsom sites are present in the upper drainage basins of the Colorado, Arkansas, Rio Grande, Gunnison, and Platte Rivers. Likewise, almost all of the excavated Paleoindian residential structures in southern Wyoming, Colorado, and northern New Mexico are found in similar headwaters settings, perhaps indicating a focus on overwintering and exploiting aggregated animal resources (Stiger 2013).

Viewed over time, of course, the great majority of sites in the Rocky Mountains postdate the Paleoindian period and in fact fall later in the Holocene, with a frequency spike in the last millennia prior to the Contact period. Many of these sites were briefly occupied summer hunting localities or had other specialized uses (e.g., Benedict I98I, I985, I992a, I992b, I996, 2000; LaBelle and Pelton 2013; Morgan et al. 2012). Far less common were high-elevation residential villages; where these occur, they appear to be summer occupations as well, though not necessarily hunting camps. At High Rise Village and other high-altitude temporary residential localities in the Wind River Range of the Rocky Mountains, for example, groups were likely exploiting seasonally available plants such as geophytes or pine nuts (Morgan et al. 20I2; Stirn 20I4; comparable purposes and patterns are seen in the high-elevation villages of the Great Basin [e.g., Bettinger I99I, 2008; Thomas 20I4, 20I5]).

Those broad temporal patterns notwithstanding, the upper drainages of the southern Rockies, particularly the Upper Gunnison Basin (UGB), are an exception. There are more known and excavated Folsom than Late Prehistoric sites, along with a spike in occupation during the Early Archaic, ca. 8,0005,500 radiocarbon years в (Reed and Metcalf 1999; Stiger 200I). In this volume, we report on a still rarer phenomenon: a longer-term Folsom residence, the Mountaineer site.

\section{THE MOUNTAINEER SITE}

Mountaineer is located in the Upper Gunnison Basin, a high-elevation region nearly surrounded by mountains on the western slope of the Continental Divide (figure I.I). The site is at an elevation of $~ 2,625$ meters above sea level (masl) atop an isolated mesa, Tenderfoot Mountain (referred to locally as "W" Mountain), ${ }^{1}$ which is situated at and overlooks the confluence of the Gunnison River and one of its major tributaries, Tomichi Creek.

Tenderfoot Mountain rises to visual prominence almost 300 meters above the floor of the UGB (figure I.2), which is itself at an elevation of 2,350 masl. 


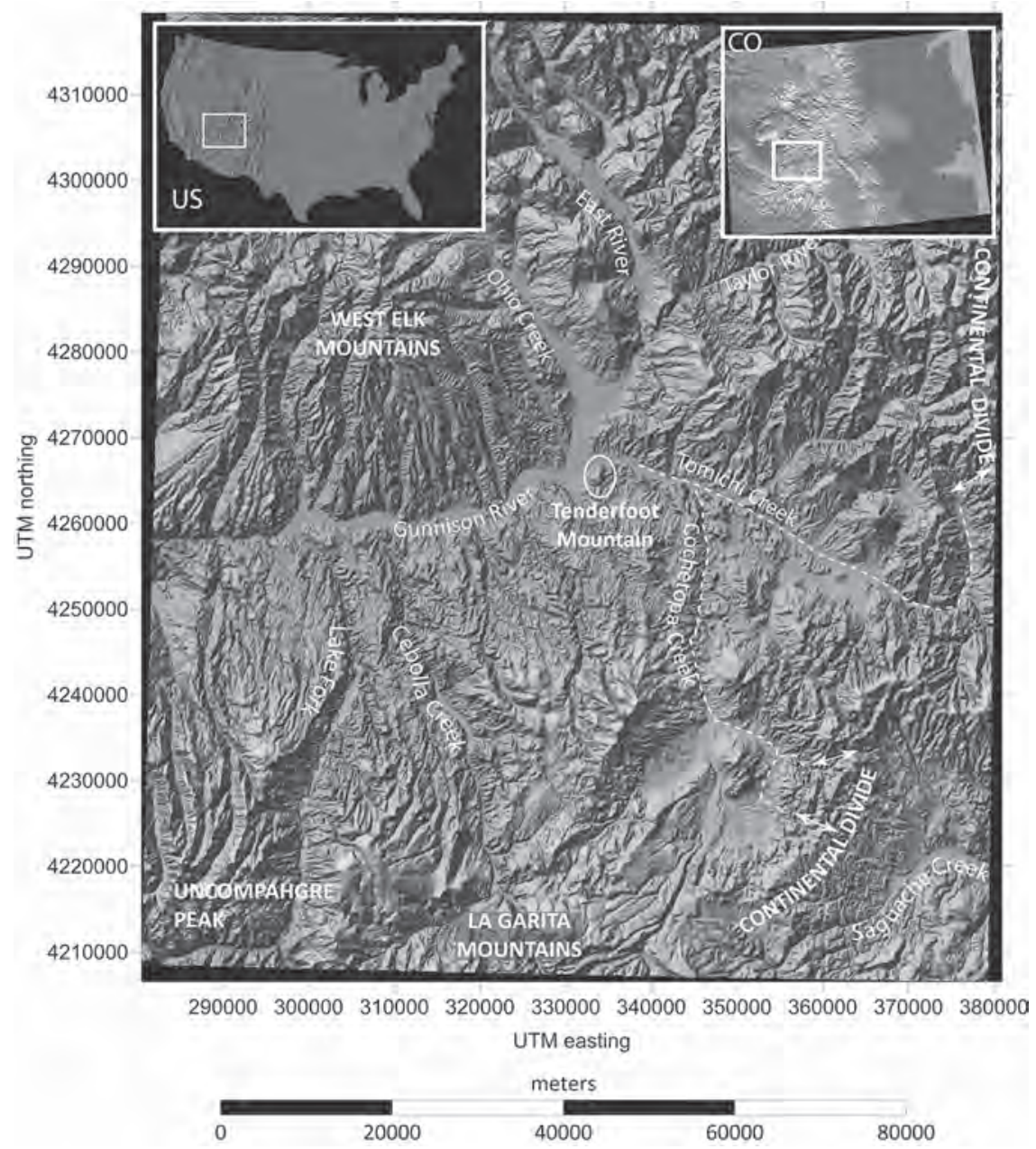

Figure 1.I. DEM location map of Tenderfoot Mountain in the Upper Gunnison Basin, Colorado

Despite the rise in elevation, the slopes of Tenderfoot Mountain are generally smooth, with routes to the top that are not particularly challenging (figure I.3). Once on top, the surface is virtually level, though overall the northern end of the mesa is $\sim 25 \mathrm{~m}$ higher than the southern end. Today, the mesa is covered in grass and sagebrush, with small groves of aspen, Douglas fir, and juniper scattered around its upper flanks, particularly in protected cornices.

\section{Copyrighted material Not for distribution}




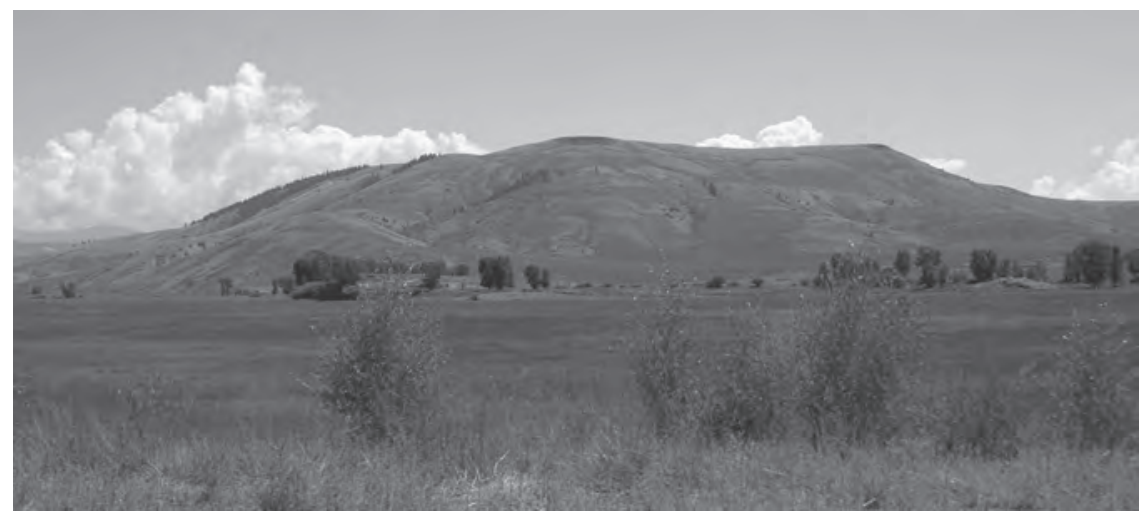

FIGURE 1.2. View of Tenderfoot Mountain rising above basin floor of the UGB, from the west

Tenderfoot Mountain is roughly lozenge-shaped in plan, $\sim 1.25 \mathrm{~km}$ long and $\sim 0.45 \mathrm{~km}$ wide, its long axis oriented a few degrees east of north. A perimeter walk around the mesa top (a distance of $\sim 2.64 \mathrm{~km}$ ) offers a commanding view of $\sim 800 \mathrm{~km}^{2}$ of the surrounding landscape. Just how much of that area could have been seen in earlier times would, of course, have depended on the amount of obscuring vegetation (figure I.4). The view to the north and west today includes the relatively level floor of the basin and the Gunnison River coming down from the north and, to the north and east, Tomichi Creek, which flows from east to west along the northwest edge of Tenderfoot Mountain and joins the Gunnison River a few kilometers west of the site. To the east, south, and southwest, the view from the top takes in numerous small drainages and low hills. This $360^{\circ}$ vantage from atop Tenderfoot Mountain was perhaps what attracted foragers to this spot in prehistoric times, as it would have allowed them to observe any large game moving across the basin floor below.

The idea that past groups spent time atop Tenderfoot Mountain was first noted in 1992 by archaeologists from Western State College in Gunnison (now Western Colorado University, hereafter WCU). In 1994, following a survey associated with the construction of wireless phone towers atop Tenderfoot Mountain, the Mountaineer site was formally recorded as ${ }_{5} \mathrm{GN}_{2477}$. It was initially classified as a rhyolite quarry and non-diagnostic lithic scatter. However, closer inspection in 2000 revealed flaked stone concentrations on the surface associated with Folsom fluted projectile points and preforms (Stiger and Bjornstad 2002, 2003). Subsequent intensive surface surveys indicated that 

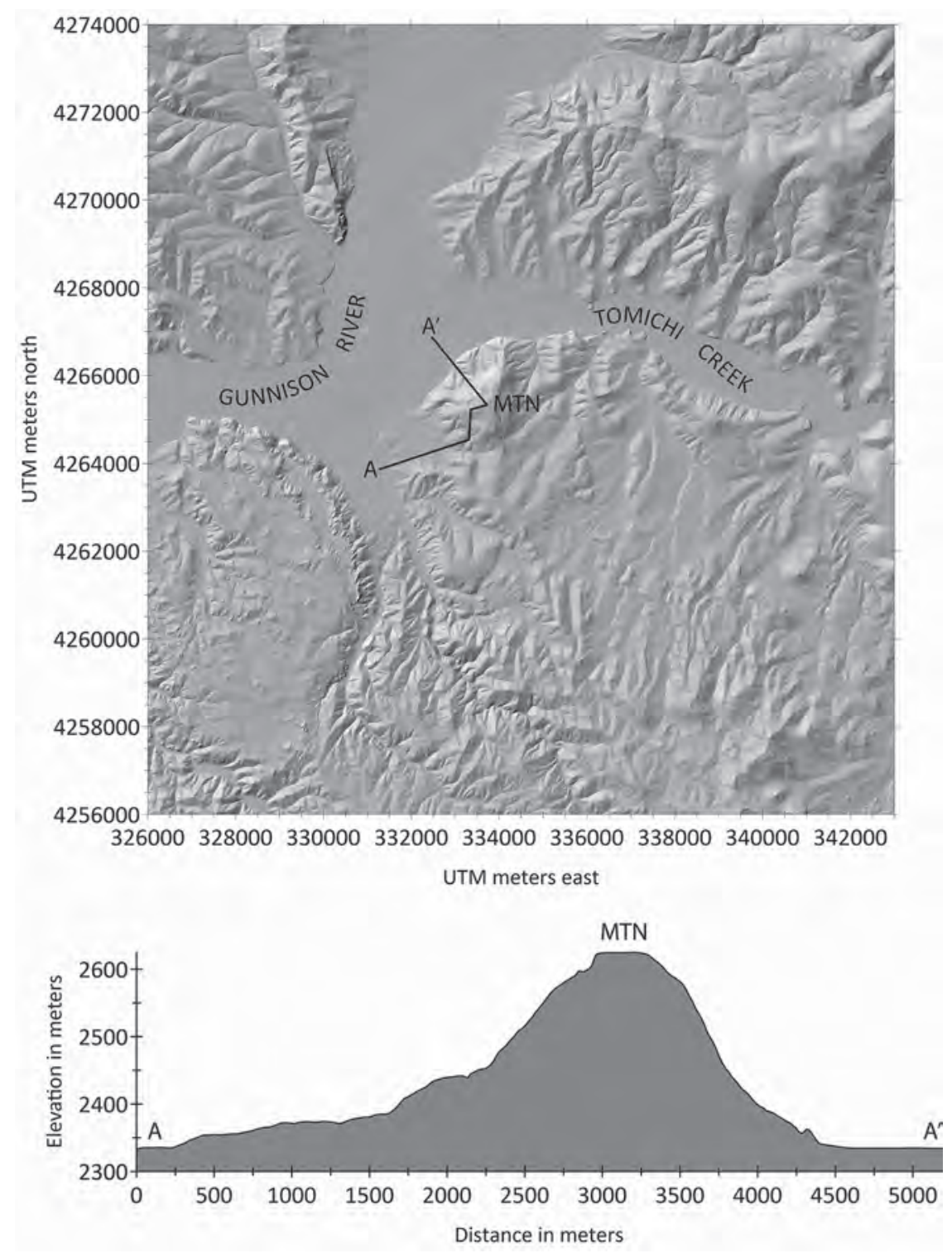

FIGURE I.3. DEM of Tenderfoot Mountain and its immediate vicinity. Bottom: vertical profiles from the basin floor to the Mountaineer site (MTN), with $5 \times$ vertical exaggeration.

\section{Copyrighted material Not for distribution}




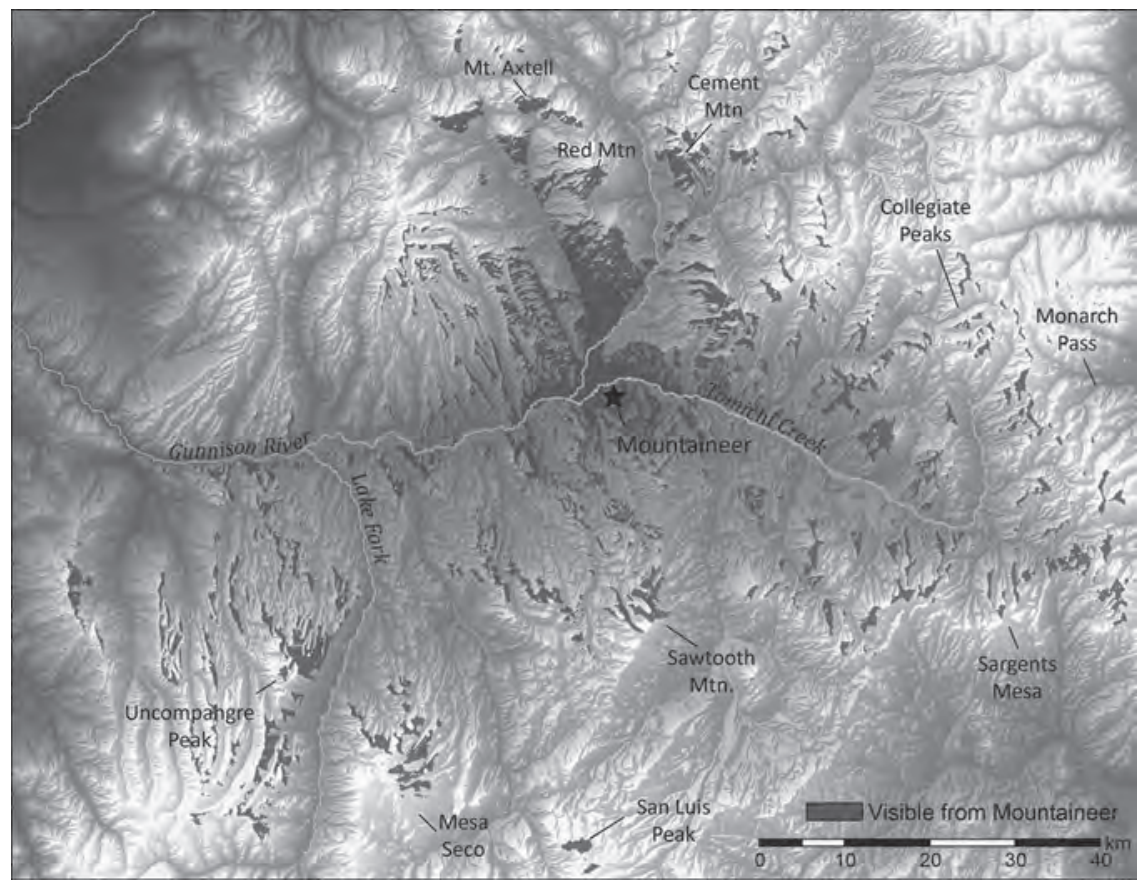

FIGURE I.4. Viewshed from a walk around the 2.64-km perimeter of Tenderfoot Mountain. The area in dark gray $\left(8 I I .5 \mathrm{~km}^{2}\right)$ is visible from the top of the mountain, indicating the extent of the immediate area hunter-gatherers could have watched for game, as well as more distant areas they could have monitored for evidence of fire, changes in the weather, or evidence of snowfall that might be expected to drive animals down to lower elevations. GIS analysis and image courtesy of Leslie Reeder-Myers.

multiple dense and spatially discrete clusters of Folsom-age artifacts were present along with scattered artifacts of later periods.

Since 2000, much of the surface of Tenderfoot Mountain has been systematically surveyed, and over $640 \mathrm{~m}^{2}$ have been excavated in five Folsomspecific cultural areas (designated Blocks A, B, C, D, and F). As part of these investigations, an additional $3 \mathrm{I}^{2}$ were excavated in two archaeologically barren "control" areas (Blocks X and Y). Over the course of investigations in the Folsom areas, more than Ioo, ooo stone artifacts were recovered from surface and excavated contexts, including ro8 Folsom fluted projectile points and preforms and almost 800 stone tools (Andrews 20I0; Morgan 20I5). The Folsom components of the Mountaineer site are scattered over I 7 hectares, making it one of the most spatially extensive known Folsom sites (Andrews et al. 2008). 
More intriguing, some of the clusters (in excavation Blocks A, B, C, and F) appear to have harbored structures. Block $\mathrm{A}$, the first to be excavated, yielded a range of stone artifacts including Folsom projectile points and preforms, knives, scrapers, and other tools, along with remains of a hearth in an area $\sim 3 \mathrm{~m}$ in diameter, cleared of the naturally occurring surface rocks (Stiger 2002). Subsequently and just to the north, excavations revealed a roughly circular distribution of large rocks ( $>35 \mathrm{~cm}$ in maximum dimension) roughly $\sim 6 \mathrm{~m}$ in diameter, which included artifacts along with charcoal, bone, and burned mud (clay) daub. The latter discovery was interpreted as the remains of a Folsomage dwelling, with the large rocks apparently arranged to form the foundation and lower walls, thought to have anchored wooden poles that served as its upper walls (Stiger 2006). The inference was warranted by several daub fragments that preserved the rounded form and bark imprint of aspen poles (Stiger 2006:figure 8; chapter 7 , this volume).

Assuming that this interpretation is correct, Mountaineer would be a rare instance of a Paleoindian site that produced traces of a habitation structure (notable other occurrences with more or less compelling evidence of the remains of structures include the Folsom component at Agate Basin, Wyoming [Frison 1982a]; the Folsom site of Barger Gulch, Colorado [Surovell and Waguespack 2007; Waguespack and Surovell 2014]; the eastern fluted point occupations at Bull Brook, Massachusetts [Robinson et al. 2009], and Thunderbird [Gardner 1983]; and the Folsom/Midland component at Hell Gap, Wyoming [Irwin-Williams et al. 1973]).

The lack of Folsom or other Paleoindian habitation structures is assuredly not because Late Pleistocene hunter-gatherers never sought shelter. Rather, and granting sampling issues, it is likely because they were highly mobile peoples who may have only briefly occupied a place on the landscape. Being less "place-oriented" (Hill et al. 2orr:766), they rarely needed to invest the labor to construct substantial, longer-lasting dwellings (Surovell 2009:66-67). We do not assume that the evidence from Mountaineer is indicative of yearlong residence at this particular spot, but that is not to preclude the possibility that it was an element of longer-term residence in the UGB (see also Kornfeld 2015:323).

Subsequent survey and excavations in the other areas at Mountaineer by WCU and Southern Methodist University (SMU, under the auspices of the Quest Archaeological Research Program) documented several more areas of the site with architectural and artifact patterns similar to those in Block A. That finding, along with clues that these marked multiple, possibly contemporaneous Folsom-age structures at the site-perhaps occupied for an

\section{Copyrighted material Not for distribution}


extended period of time-makes the Mountaineer site unusual and worthy of archaeological attention.

\section{PALEOINDIANS IN THE ROCKIES}

That said, the presence of a Folsom site in the Rocky Mountains and more specifically in the southern Rocky Mountains is not unprecedented (Andrews 2oro; Pitblado 20I6; Pitblado and Brunswig 2007). Reports of isolated surface finds of Folsom and "Folsom-like"2 points in the region began to appear in the I930s and I940s, following the widespread recognition of the age and significance of these distinctive forms (Hurst I94I, I943, I945, I947; Huscher 1939; Wormington 1944, 1949). However, early on it was uncertain whether there had been a Paleoindian presence in the mountains, an idea most vigorously promoted by Hurst (e.g., I943), or if these isolated finds were-as Wormington (I944:II, 1949:24) suggested-dropped by visiting hunters who were otherwise "largely, although not entirely, confined to the High Plains area."

This question arose because early discoveries of Paleoindian sites were largely confined to the Great Plains and were associated with the bones of large mammals. This pattern was a consequence of the manner in which Paleoindian sites were then often found: by searching for artifacts at localities where large mammal bones had been spotted (Meltzer 2006a, 2006b). It led to the inference that Paleoindians were big-game hunters, and as their prey were considered denizens of the Plains grasslands, it was likewise assumed that this was the region principally inhabited by Paleoindians, a view codified in syntheses in the I940s and I950s (e.g., Roberts 1940; Sellards 1952; Wormington 1939, 1944, 1949).

More important, however, this view was not just about where Paleoindians were. There was also a strongly held view of where they were not: the Rocky Mountains. That notion was first explicitly expressed in the mid-1950s by Jennings and others (1956) as the Desert Culture concept. The Desert Culture involved the "intensive exploitation of the environment, [which was] nonspecialized in the sense of no major reliance on one resource, but close adaptation to everything available including small mammals such as rodents" (Jennings et al. 1956:70). That adaptation was thought to extend over an area "from Oregon to the Valley of Mexico and from the eastern foothills of the Rocky Mountains to the Pacific Coast" (Jennings et al. 1956:69). The Desert Culture was "distinguishable in its culture pattern from the big-game hunting tradition exemplified by Folsom and similar finds" and used a technology "sufficiently distinct from that of the Paleo-Indian big-game hunters to testify not 
only to a quite different environmental adaptation but to a different cultural outlook as well" (Jennings et al. 1956:71).

The Desert Culture concept was highly influential, so much so that for decades the occurrence of fluted and other Paleoindian projectile points in the Rocky Mountains was routinely attributed to Paleoindians who were only ephemeral visitors to the region or perhaps to the transport of projectile points by later groups into the mountains (Frison 2007; Pitblado and Brunswig 2007).

The apparent absence of Paleoindians in the Rockies fit nicely with the conventional view of Paleoindian adaptations and the availability of their supposedly "preferred" prey. As it was thought that big game such as bison and mammoth only infrequently ventured into the mountains (e.g., Bergtold I929; Cook 1930, 1931; Fryxell 1926, I928), it made sense that specialist big-game hunters were likewise infrequent visitors. The high-elevation environments of the Rockies were thought to have "held little interest" for peoples adapted to the hunting of these big-game species (Husted 1974:865).

The apparent absence of early Rocky Mountain Paleoindians was reinforced by cultural resource management work in the r 980 os and I99os in the UGB, which failed to reveal any significant sites of this age (Black r99r; Jones I984, I986, I996; Stiger 200r; Stiger and Carpenter 1980). Work by Pitblado (1998:337) in the southern Rocky Mountains that same decade came to a similar conclusion. Likewise, in the Colorado Front Range, Benedict (1992a:345) observed that "evidence for occupation prior to I0,500-IO,000 B.P. remains inconclusive. It consists of a single Clovis projectile point and single Folsom projectile point, both of which could have been carried into the mountains as amulets by later people."

Nonetheless, it became apparent by the late I990s that Paleoindians in postFolsom times had occupied the region, possibly even doing so "on a full-time basis" (Pitblado 1999:439), a conclusion based on inferences drawn from patterns of point typology, technology, and raw material use. As to why evidence of early Paleoindians remained elusive, Pitblado (I998:340, I990) suggested that Late Pleistocene geological processes may have effectively buried or destroyed such evidence but maintained the idea that the low densities of early Paleoindian projectile points reflected their overall scarcity in the area. ${ }^{3}$

Nonetheless, the number of known Folsom locales and surface finds of diagnostic Folsom tools in the Rockies slowly began to increase in the last decades of the twentieth century and the first decade of the twenty-first century. The Bighorn Mountains and Bighorn Basin in Wyoming produced evidence attesting to both Clovis and Folsom presence (Finley et al. 2002, 2005; Frison 1976; Frison and Bradley 1980; Frison and Todd 1986; Ingbar 1992, 1994; Zier

\section{Copyrighted material Not for distribution}


TABLE I.I. Folsom-age sites in the UGB

\begin{tabular}{lll}
\hline Site Name & Site Number & Reference \\
\hline${ }_{5} \mathrm{GN}_{240}$ & ${ }_{5} \mathrm{GN}_{240}$ & Chambellan (I 984) \\
Atopa WAPA & ${ }_{5} \mathrm{GN}_{3} 85 \mathrm{I}$ & Stiger (unpublished data) \\
Bob's Folsom & ${ }_{5} \mathrm{GN}_{3} 849$ & Stiger (unpublished data) \\
Flat Top & ${ }_{5} \mathrm{GN}_{3} 850$ & Andrews and Meltzer (2005); Meltzer (2009b) \\
Highway Cleaning & ${ }_{5} \mathrm{GN}_{3553}$ & Stiger (unpublished data) \\
Lanning & ${ }_{5} \mathrm{GN}_{5} \mathrm{I}_{\mathrm{I}}$ & CAS (I997); Dukeman (2005, 2006) \\
Mountaineer & ${ }_{5} \mathrm{GN}_{2477}$ & Stiger (2006) \\
Singing Antelope & ${ }_{5} \mathrm{GN}_{3} 854$ & Stiger (unpublished data) \\
Soderquist & ${ }_{5} \mathrm{GN}_{246}$ & LeIstman and Gilmore (I988) \\
\hline
\end{tabular}

et al. 1987). Further south, indications of a significant Folsom occupation were recovered in Middle Park, Colorado (Kornfeld and Frison 2000; Surovell and Waguespack 2007), in the San Luis Valley (Jodry 1992, I999a, I999b), and in a high-elevation headwaters tributary of the Rio Grande (Jodry I999b; Jodry et al. 1996). In the UGB, at least nine Folsom sites and numerous isolated surface finds have been identified, only three of which were documented prior to the turn of the century (table I.I).

Folsom sites are now known to occur in the Rockies (Pitblado and Brunswig 2007; Stiger 2006). They remain relatively rare, but then compared to later periods, the archaeological record of Folsom hunter-gatherers is generally relatively sparse in all physiographic settings. There is no compelling reason to suspect the situation to be different in mountain settings. It is also now apparent that bison were present in Folsom times in intermountain areas like Middle Park and the San Luis Valley (Jodry 1999b; Pitblado and Brunswig 2007:64). Bison availability as prey was not necessarily a limiting factor on Folsom hunter-gatherers in the UGB. Although bison were undoubtedly economically important, they were probably not at all times and in all places the sole or most important factor driving Folsom occurrences (Andrews et al. 2008; Kornfeld and Larson 2008; LaBelle 2005, 2012).

For hunter-gatherers in general and, by extension, groups in the UGB, predictable non-mobile resources such as lithic raw materials, wood, potable water, small game, and plants probably played a significant role in determining adaptive and land-use strategies (Andrews et al. 2008; Binford 2001:276; Hill et al. 20Ir:755-756; Morgan et al. 20I2; Surovell 2009:226). Settings like the UGB could have offered Folsom hunter-gatherers bison and other large game

\section{Copyrighted material Not for distribution}


(e.g., elk), as well as relatively more abundant and predictable non-mobile resources than may have been available in more monotypic Plains settings, though that would vary by the season of occupation.

Stiger (2006) suggested that Mountaineer was occupied for an extended period, perhaps over the winter months. Were that the case, it would have been a challenging setting. The UGB is today one of the coldest regions of North America; January minimum temperatures average $-6^{\circ} \mathrm{C}$ (chapter 3, this volume). It would not have been significantly warmer in Folsom times, which fall within the Younger Dryas Chronozone (YDC), a millennium-long span of the terminal Pleistocene when global climates cooled to near glacial conditions. By then, the glacial complexes that once overrode the nearby Continental Divide (many over $\sim 4,265 \mathrm{~m}$ elevation) had vanished (Brugger 2006, 2007; also Pierce 2003). Yet even if the YDC was not glacially cold in the Gunnison region, it was assuredly cooler than in prior millennia or in subsequent Holocene times (Briles et al. 2012; Fall 1997b; Reasoner and Jodry 2000).

Regardless of the season of occupation, with its multiple, possibly contemporaneous structures onsite, Mountaineer has the potential to shed light on aspects of Folsom period archaeology and adaptations that are otherwise little known (Surovell 2009).

\section{FOLSOM ARCHAEOLOGY AND}

\section{ADAPTATIONS: A BRIEF OVERVIEW}

In the decades following the discovery of the Folsom type site, scores of Paleoindian sites were discovered (Meltzer 2006b). Of those, two greatly influenced views of Folsom as a cultural complex and what it represented of past behavioral systems (Hofman 2002): the type site in New Mexico, excavated from 1926 through I928, and the Lindenmeier site in the eastern foothills of the Rockies in northern Colorado, investigated half a dozen years later (Gantt 2002; LaBelle 2012; Roberts 1935, I936, I937; Wilmsen and Roberts 1978). The differences between them established a fundamental dichotomy in Folsom site types between Folsom kills and Folsom camps.

Work in subsequent decades expanded this typology, introducing other site "types" and defining the expected assemblage characteristics at each (e.g., Dawson and Judge 1969; Hester 1962, 1972; Irwin-Williams et al. 1973; Judge r973; Surovell 2009; Wendorf 196r; Wendorf and Hester 1962; Wendorf et al. 1955). Significant contributions were also made to the understanding of Folsom lithic technology, in particular to the process of Folsom projectile point manufacture, use, and discard. Models of Folsom settlement behavior, however, continued to

\section{Copyrighted material Not for distribution}


be defined as spatially exclusive kills and camps. As Hofman (2002:407) notes, "The essential model was that bison hunts were launched from a fixed campsite and the products of successful hunts were returned to that camp."

That view of Folsom sites as dichotomous types began to change in the early I980s with Frison's (1982a) documentation at the Agate Basin site in eastern Wyoming, with Folsom-age kill and camp areas within the confines of the same locality. Also in 1982, a preliminary report on the Cattle Guard site in the San Luis Valley of Colorado appeared, which indicated that there, too, were both kill and camp areas (Emery and Stanford 1982). This pattern of linked kill and camp areas was subsequently observed at a number of other Folsom sites and played a major role in the formation of the ideas concerning early Paleoindian land use that were essential in the arguments presented by Kelly and Todd (1988). They suggested that the pattern of Folsom occupations located next to small bison kills "may be indicative of a system in which residential groups moved from kill to kill" (Kelly and Todd I988:236). Further work at the Cattle Guard site documented what proved to be a large bison kill and associated processing activities and a camp (Jodry 1992, I999a; Jodry and Stanford I992) and provided a detailed illustration of what an individual kill site within the "kill to kill"—or what came to be called

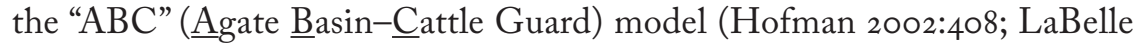
20I2) - might look like.

The "ABC" model of Folsom subsistence and mobility at first glance seems substantially different than the original "kill or camp" model. The sometimes spectacularly long distances represented in raw material movements by Folsom groups (Hofman I99I, I994, I999a; Jodry 1999a; Surovell 2009:22I-229) certainly suggested frequent and extensive mobility. It was noted, however, that social alliances and trading or gift exchange between geographically separate groups or the movement of individuals (as opposed to residential groups) might be responsible for at least some occurrences of exotic stone (Bamforth 2002, 2009; Jodry 1999a; MacDonald 1998, 1999).

Regardless, the high residential mobility of Folsom groups seems to have been seasonally constrained, possibly to different times of the year in the northern versus the southern Plains (Surovell 2009). There also appeared to be evidence that mobility was geographically constrained (Amick 1994; Andrews et al. 2008; Bamforth 2002), occurring most frequently in ecologically monotypic settings such as the Plains and in other raw material-poor areas. The shift away from the "kill or camp" model to the ABC model also resulted in a shift away from focusing on logistically organized offsite foraging behavior (Andrews et al. 2008), though it is generally recognized that this was an 
important element of Folsom foraging (Hofman and Ingbar 1988; Kelly and Todd I988:238).

The $\mathrm{ABC}$ model involves some portion of time being spent in residential bases, with provisioning taking place through the use of logistically organized hunting parties. Movement of the entire residential group presumably only occurred when some perceived cost-benefit threshold of staying versus moving was crossed. The general consensus, outlined by Kelly and Todd (among others), is that this threshold was crossed fairly quickly after a kill was made, thereby requiring almost constant residential mobility. Situational variability was undoubtedly involved in the decision to move the residential group or remain in a given area, and it is likely that during certain seasons or at certain locations, Folsom groups may have remained in a residential camp for significant periods, certainly longer than that generally implied by the ABC model (Andrews et al. 2008; Surovell 2009:222). In such cases, understanding the day-to-day logistical foraging component of the mobility system would be extremely important. In general and as earlier noted, areas with good access to predictable, non-mobile resources such as stone, wood, and water could have been occupied for relatively longer periods, though that would have depended on factors such as the structure of the environment and the season of occupation-with winter snow cover, for example, increasing the cost of residential mobility (Surovell 2009:222-223; also Andrews et al. 2008; Binford 200r:276; Hill et al. 20rr:755-756). Unfortunately, even coarse estimates of the actual length of residential occupations are hard to come by (but see Surovell 2009:table 8.I).

The ABC model has influenced and arguably guided Folsom research over much of the past three decades and recognizes the importance of logistically organized hunting. Nonetheless, the model focuses somewhat narrowly on what is considered the more important component of frequent residential mobility: its effects on social and technological organization. At the heart of the $\mathrm{ABC}$ model is the assumption that Folsom groups were specialized bison hunters. This assumption, in turn, has had a profound effect on the study and interpretation of all other aspects of behavioral adaptations. The exclusive (or near exclusive) hunting of mobile game is argued to have required a strategy of frequent residential movement to track and maintain access to herds. A very high level of mobility thus became the defining behavioral characteristic of Folsom groups-a characteristic thought to have influenced most other aspects of Folsom behavior. Highly mobile bison hunters were said to utilize reliable, high-quality lithic materials, efficient bifacial core and tool technologies, and a highly conservative projectile point design to mitigate the costs of

\section{Copyrighted material Not for distribution}


frequent residential mobility (e.g., Ahler and Geib 2000, 2002; Goodyear 1979; Hofman I999a, 1999b, 2002; Kelly 1988, I996, 1999, 2003; Kelly and Todd I988; MacDonald 1998, 1999; cf. Bamforth 2009; Speth et al. 2013).

In principle, the $\mathrm{ABC}$ model squares well with our understanding of the role of hunter-gatherer mobility. Without putting too fine a point on it, mobility is a first-order solution to many of the challenges hunter-gatherers face. Are resources declining? Move. Is winter coming? Move. Are there difficulties within the group? Fission, and then move. As our longtime colleague Lewis Binford (1980) often said, mobility is insurance for huntergatherers. Mobility is also a primary means of gathering information about when to move, where to move, and how to move-all of which is vital to groups on a sparsely populated and still relatively unknown landscape (Hitchcock and Ebert 20Ir; Kelly 20I3; Meltzer 2003, 2004, 2009a; Whallon 2006). Of course, mobility brings its own challenges: for example, huntergatherers have to cope with environments that can be patchy in time and space, make logistical decisions about allocating time and how/when to move between resource patches factoring in travel costs, and-of particular interest in regard to early groups in North America such as Folsom-how to move across landscapes about which they may have relatively little or even no prior knowledge (Meltzer 2002).

The ABC model has served as an important frame of reference for much of what is known about the nature of sites occupied by Folsom groups on the move, about their subsistence strategies, hunting and processing strategies, stone tool technology (particularly the manufacture of the iconic Folsom projectile points), and their mobility and organizational strategies. Yet the ABC model is based primarily on research on Great Plains Folsom sites, the presumptive heartland of the Folsom complex (Frison I99r; Holliday 2000). It fits well with the archaeological data from that region, though that might in part be a result of biases in site discovery and sampling (Hill et al. 20Ir:766). Nonetheless, in such ecologically monotypic settings, where there are low numbers of species but high numbers of individuals per species, this sort of specialized adaptive strategy makes sense (Jochim r981; Meltzer 1993).

Regardless, the net result is that we have a good idea of what a Folsom group looked like when on the move. What we largely lack is evidence of what happened when they stopped, as virtually all Late Pleistocene hunter-gatherers outside the tropics must have done on occasion when circumstances made mobility difficult or impossible (Surovell 2009:222-223). What are the conditions that influenced and accompanied the decision to stay rather than to go (Hill et al. 20Ir:754)? 


\section{THE CHALLENGE OF NOT MOVING}

When faced with constraints on mobility, hunter-gatherers are forced to modify their behavior. Over the long span of prehistory, increased population density limited the mobility option, resulting in a series of evolutionary changes in culture that eventually gave rise to new forms of subsistence, technology, and social organization (Binford 200I). But early hunter-gatherers in North America were not faced with constraints on mobility imposed by densely packed populations. Rather, it was the opposite: they had to deal with problems stemming from the relatively low population density of North America at that time- problems that could be solved through mobility. Information about the location of food resources, stone raw materials, or potential mates, for example, could be most efficiently gained through frequent movement over the landscape (Hitchcock and Ebert 20II; Lovis and Donahue 2orr; Meltzer 2009a; Speth et al. 2013; Whallon 2006, 20II).

But other factors, such as the season or the size and composition of the group, could have limited the mobility of an otherwise unbounded group of Folsom hunter-gatherers and impacted their residential mobility. This raises the question of whether there were seasons and places where they might stop. Or, once stopped, how long they might stay, and what strategies they might employ to mitigate the costs of staying in one place for a relatively long period of time. In many respects, stopping can be more costly than moving, not least because it removes the hunter-gatherers' insurance policy. Where they stopped, what they did when stopped, and how they may have coped with contingencies such as resource depression while stopped are of great interest and potential significance.

These types of questions have generally not been asked of the Folsom archaeological record, in part as a result of the focus on the ABC model, the dearth of residential sites, and because the most prominent and best-known sites of this age are bison kill and processing localities found primarily on the Great Plains-such as Cooper (OK), Folsom, and Lipscomb (TX)—and lithic workshops such as Adair-Steadman (TX) and the constellation of Lake Ilo (ND) sites: Big Black, Bobtail Wolf, and Young-Man-Chief (Bement I999b; Jodry 199r; Meltzer 2006a; Root 2000; Tunnell I977; William 2000).

Consequently, far less is known of the types of activities that are more likely to be apparent in longer-term residential occupations (Hill et al. 2orr; LaBelle 2005). For example, however transient Folsom and other early groups were, they assuredly prepared and made use of shelters of some form. Yet, as noted, few are known and most were ephemeral, hinted at by post molds (IrwinWilliams et al. 1973; Knudson 2009), areas of hardened earth interpreted as

\section{Copyrighted material Not for distribution}


prepared floors (Frison and Bradley 1980), bison ribs driven into the ground in a manner to suggest use as tent pegs (Frison I982a: 39-40; Hill 2008), or the spatial distribution and concentration of hearths and artifacts (Hill et al. 2orr; Surovell and Waguespack 2007; Waguespack and Surovell 20I4). The possible structure(s) at Mountaineer, with their apparent rock foundation and walls, are especially unusual for the Folsom time period.

Likewise, residential sites offer the potential to investigate the secondary and more intensive processing of food sources and prey species, meat and hide preparation, refurbishment and "gearing up" of weaponry, and the construction of shelters-particularly ones that might have been built to withstand the cold of the long winter months of the Late Pleistocene (LaBelle 2005). Such sites have the potential of revealing a greater diversity and representation of tool forms and debitage, and they provide a very different vantage on technological organization, settlement scale and mobility, and other habitation activities (e.g., Bamforth 2002, 2009; LaBelle 2005; Sellet 2004; Surovell 2009).

As one of the very few extensively excavated, potentially longer-term Folsom occupations possibly containing structures, Mountaineer is ideal for asking and answering questions about what Folsom groups did when they stopped moving. But why, if they did stop, might they have chosen this high-elevation basin in the Rockies?

\section{THE UPPER GUNNISON BASIN AS A HUMAN HABITAT}

The Upper Gunnison Basin is almost entirely encircled by mountain ranges with elevations of at least 3,050 m (figure I.I), through which there are a limited number of mountain passes to adjacent regions, such as the San Luis Valley to the southeast (chapter 3, this volume). The narrow, steeply walled Black Canyon of the Gunnison River limits easy access to the Colorado Plateau to the west. The UGB's relative topographic isolation has resulted in a climatic and biotic system somewhat different from other larger montane basins (Emslie I986; Scott I986). Its small size $\left(\sim \mathrm{II}, 000 \mathrm{~km}^{2}\right)$ and extreme relief concentrate vertically stratified ecological zones in short horizontal distances (Daubenmire 1943; Marr 1967; Peet 1978; Prather 1999), a factor with potentially important implications for foraging behavior. Unlike areas of the Great Plains where Folsom groups had to acquire stone from distant sources, highquality lithic raw materials (both chert and quartzite) are available throughout the UGB (Black 2000; Stiger 200I).

Living in a high mountain environment both poses challenges and provides benefits for hunter-gatherers. ${ }^{4}$ As part of his work in the south-central 
Andes, Aldenderfer (1998) outlined five characteristics of mountain environments that bear on the strategies employed by hunter-gatherers. Aldenderfer presents these characteristics - low primary productivity, high instability and fragility, environmental heterogeneity, extremeness, low predictability-as challenges to be solved by hunter-gatherer groups. Although these are a concern in the Andes (and perhaps in other ranges and regions), in the Gunnison Basin most of these characteristics are either less of a concern or, in fact, can be advantageously exploited with certain adaptive strategies (Kornfeld 20I3:IO).

Moreover, environmental processes at one scale can obscure significant variability at another scale. For instance, on the principles that higher elevations have colder temperatures and higher precipitation, Aldenderfer (I998:18) described a model of mountain cultural adaptation in which high-elevation regions $(>2,500 \mathrm{~m}$ ) "are not habitable due to extremely cold temperature and the hazards of heavy snowfall, which can prevent any degree of mobility for much of the winter. Typically, foraging peoples use high mountains extensively during a relatively short period of time, roughly late spring until early fall, either on a residential or logistical basis." Yet snow and cold are not simply correlated with elevation. Further, the assumption that humans universally avoided snow and cold because they are dangerous, uncomfortable, and impediments to travel, food acquisition, and survival is not borne out by the ethnographic or the archaeological record. In some regions, winter snows can help concentrate game, though too much snow can have a catastrophic impact on animal populations (Coughenour and Singer 1996; Frison 2004; Marchand 2013; Wallmo and Gill r971).

Mountain regions can also be rich sources of plants and animals. The biological richness of an area has been described by caloric production per unit area, commonly measured as Aboveground Net Primary Productivity (ANPP) or primary productivity (Leith and Whittaker 1975). Measurements of ANPP in western North America demonstrate that in general, primary productivity increases with elevation from low foothills to peak production between 2,500 and 3,000 masl; above that, ANPP declines in the high alpine and above treeline zones (figure I.5) (Darling 1966; Gholz 1982; Gosz 1980; Grier et al. 1989, 1992; Moir and Frances 1972; Pearson 1965; West 1988; Whittaker and Niering 1975).

These relative differences in ANPP show that the ecological production of landscapes can vary greatly. As pointed out by Hunter-Anderson (I986) and Osborn (1993), compared to low-elevation areas of the Southwest, mountains are islands of productivity in a desert sea, especially for hunter-gatherers. Whatever the direction of approach to the southern Rocky Mountains, productivity increases with elevation. Like all other factors of high mountain

\section{Copyrighted material Not for distribution}




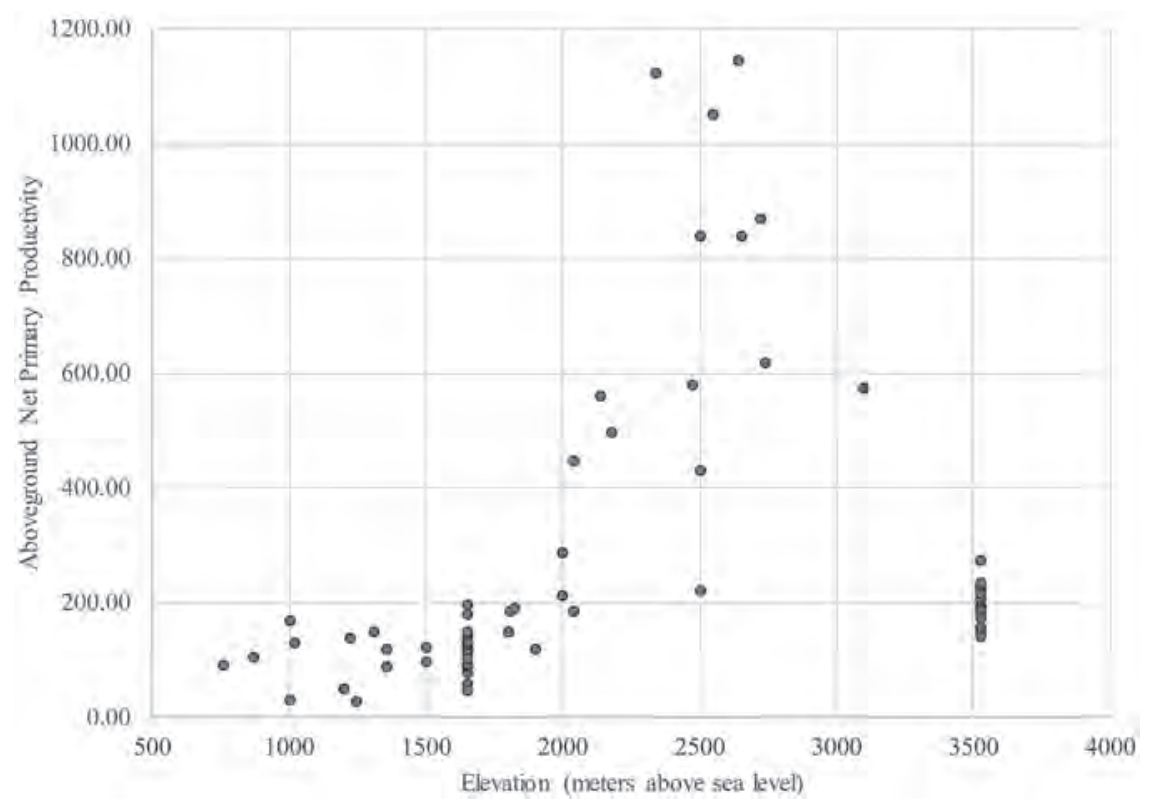

FiguRE 1.5. Empirical measurements of ANPP around the southern Rocky Mountains, which demonstrate that primary productivity increases with elevation from low foothills to peak production between 2,500 m and 3,000 m. Data from LTER Network Data Portal, https://portal.lternet.edu/nis/home.jsp.

environments, though, ANPP is highly variable and dependent upon local conditions, such that there may be individual valley systems, ecological zones, or patches within the overall environment with relatively high (or low) primary productivity.

Certainly, in areas of low primary productivity, rapid changes in temperature or precipitation or the destruction of a particular resource base can severely impact and even cause the local extirpation of floral or faunal components of the ecosystem (Ives 1985; Koteen 2002). This circumstance can potentially be relevant in a topographically bounded setting such as the UGB, where species can become "trapped" as relict populations and more susceptible to extirpation (e.g., the Gunnison Sage Grouse [Young et al. 1994, 2000]). Once a species was locally extinct, it would have been difficult to reestablish from populations in neighboring regions owing to the high-elevation barrier surrounding the UGB. Piñon pine, for example, was present in the UGB between

\section{Copyrighted material Not for distribution}


8000 and 3000 в р but subsequently disappeared (Emslie et al. 2015). Despite present environmental conditions suitable for its growth (Markgraf and Scott I981; Stiger 200I), piñon pine is slowly making its way back into the UGB via passes over the Continental Divide.

Extremeness, predictability, and heterogeneity are closely linked in mountain environments. Environmental and climatic parameters such as temperature, precipitation, and wind are highly variable in the mountains but often include periods of extreme cold, high winds, and heavy seasonal snows that limit the human occupation of some areas but can also serve to concentrate prey resources in other areas. The variable nature of such conditions can lead to low predictability in the timing and location of important resources and resource patches. Direct measures of overall predictability for any given environment are difficult to obtain. Aldenderfer (1998) suggests that montane systems are generally characterized by very low predictability, which may be true of specific resources or mountain ranges, but overall predictability in an ecosystem like the UGB was probably not so low that it greatly affected huntergatherers. In winter, knowing that game would be forced down in elevation, predictability may have been high.

Regardless, low predictability can be offset by heterogeneity in resource patch characteristics. Patch size, composition, distribution, longevity, and productivity can be highly variable both spatially and temporally. In some areas of the Gunnison Basin, elevation changes of more than $\mathrm{I}, 000 \mathrm{~m}$ are found over horizontal distances of less than $20 \mathrm{~km}$, leading to significant differences in biota across relatively short distances. By organizing mobility and foraging strategies around this relatively close "packing" of elevation-controlled resource zones, hunter-gatherers could offset many of the challenges of living in a montane environment.

In studies of modern uses of montane environments, Thomas (1979) argues that most mountain-dwelling groups share a number of adaptive strategies. These include a diverse resource base, an emphasis on maintaining accurate knowledge of important patch conditions, and a high degree of behavioral flexibility at the individual, household, and community levels. Such strategies allow groups to effectively harness the environmental heterogeneity of montane environments, making heterogeneity an asset rather than a constraint. In terms of risk, maintaining a diverse subsistence base through exploitation of vertical zones of production is arguably less risky than a more specialized subsistence base, such as that found among Folsom groups in the Great Plains. As Frison (1978:I3) long ago observed, "narrow economic specializations were often the road to disaster."

\section{Copyrighted material Not for distribution}


The two commonly held assumptions, that humans avoid cold and snow and that mountains are food-poor environments, cast these settings as barren regions only to be retreated to as a last stand and under extreme circumstances, as supposed early on by Kroeber (1939), Steward (1938), and others. It was long assumed that occupation of the Rocky Mountains must have been a relatively late phenomenon in prehistory. That, in turn, suggested that the occupants of high mountain regions must have been derived from earlier populations living elsewhere who were perhaps forced by "deteriorating" climate to leave their original homelands (e.g., Benedict 1979; Benedict and Olsen 1978; Black 199r; Hurt 1966; Lister 1962; Pitblado 1998; Sheehan 1995; Wormington and Forbis 1965).

Yet despite the long-standing view of the mountains as harsh and inhospitable for human occupation, mountain environments are not inherently more difficult to occupy than lowland ones. As in any setting, there are challenges that must be solved. Certainly, the UGB is cold, and it was likely even colder during the terminal Pleistocene. Topographically, it was isolated-passage into and out of the basin was likely difficult for pedestrian hunter-gatherers, especially during periods of heavy snowfall (LaBelle 20I2). Of course, the same would have been true for prey species as well, which would have shifted down to lower elevations in winter, providing hunters with access to a spatially confined but diverse set of resources (Kornfeld 2013; Surovell and Waguespack 2007). Such circumstances could have made resources easier to find and capture than in a topographically unbounded environment like the Great Plains, where food sources may become spread out over great distances.

\section{THE MOUNTAINEER SITE: SOME QUESTIONS}

Mountaineer is large in terms of its spatial extent and its assemblage size and appears to be mostly intact spatially; thus it provides a valuable opportunity to study the nature and organization of a possible Folsom residential site. Our goals in this volume are threefold: (I) to summarize the results of over ten years of excavation and research at Mountaineer, (2) to provide essential data on the site to interested researchers, and (3) to address a series of specific questions regarding the Mountaineer site and its place in the overall Folsom archaeological record. Those questions include the following:

Are there one or more built structures onsite, and are they demonstrably Folsom age?

\section{Copyrighted material Not for distribution}


If there are multiple structures or activity areas onsite, do they represent a single contemporaneous occupation or repeated visits to the locality?

What was the season of occupation of the site?

What activities took place in the different areas/structures, and if they were contemporaneous, were the different entities on the site functionally independent or interdependent?

What do these structures and their artifact assemblages reveal about the duration of occupation at the site?

Was the site occupied for an extended period, and how did the length of the occupation impact the activities that took place and influence the character of its archaeological assemblages in terms of technological organization, functional stone tool classes, and raw material patterning?

What do these structures and assemblages reveal of the subsistence and settlement activities in the Upper Gunnison Basin?

More broadly, how does the Mountaineer site fit the context of Folsom period adaptations and expand our understanding of human use of the Rockies in Late Pleistocene times?

These questions will help guide the discussion throughout the individual chapters.

To address the questions, we first turn to a discussion of the geology, taphonomic history, and geochronology of the locality. Mountaineer is an open air site, shallowly buried atop an isolated mesa. Its site formation history has been influenced by numerous processes, such as freeze-thaw, bioturbation, trampling, natural fires, and modern usage of the site surface. The ways these may have impacted the integrity of the archaeological record, including efforts to determine the age of the occupation of the site, are discussed in chapter 2. That chapter also provides a discussion of the toolstone resources that would have been available in the UGB to Folsom hunter-gatherers.

Folsom groups were in this region during the Younger Dryas Chronozone, but the expression and impact of the YDC varied widely across North America (Meltzer and Holliday 20Io). Chapter 3 uses evidence of the present environment of the Upper Gunnison Basin and studies of its Pleistocene glacial, faunal, and vegetation history (e.g., Briles et al. 2012; Brugger 2006, 2007; Fall 1997b; Reynard et al. 2015) to gain insight into the environmental stage on which Folsom groups were operating and resources that may have been available.

\section{Copyrighted material Not for distribution}


The core of the archaeological data is presented in chapters 4 -II. Chapter 4 summarizes the history of fieldwork at the site, the survey and excavation procedures used, and the location and extent of the areas examined. Because the work was conducted over the course of the decade and by different teams, there was some variation in the approaches taken; these are described to clarify any differences and potential biases in the archaeological data recovered at the site. Finally, chapter 4 introduces the excavations conducted in Blocks X and $\mathrm{Y}$, two areas of the site in which no evidence of structures or other material traces of Folsom activities were sought or expected.

Work in those two blocks was undertaken principally to better differentiate archaeological from non-archaeological elements and remains, in two respects. For one, there is the challenge of how to recognize a Folsom structure. The large rocks forming the apparently circular foundations and collapsed walls of the presumed structures are no different from the large rocks strewn across the surface of Tenderfoot Mountain, and which comprise its near-surface bedrock. Hence, scrutinizing the possibility that these circular arrangements might be natural is critical. Second, occurring in greater or lesser density at the site are fragments of bone, charcoal, daub, opal-CT, rhyolite that occurs in the bedrock and flakes naturally but could be used culturally, and burned areas-all of which need to be understood in their "background" context to better assess their origin and gauge their significance when they occur in areas of the site where Folsom materials are concentrated.

The excavations in Blocks $\mathrm{X}$ and $\mathrm{Y}$, detailed in chapter 5 , involved collecting data on the size and provenience of large rocks, along with the recovery of material remains from areas of the site otherwise lacking in archaeological evidence. Following in that same chapter is the first of two analytical passes through those data. The data from Blocks $\mathrm{X}$ and $\mathrm{Y}$ are compared to Block $\mathrm{C}$, an area in which diagnostic Folsom artifacts and a possible structure were concentrated. Comparisons include the number and size and context of large bedrock blocks and the material remains that occurred (or not) in these different areas. Chapter 6 then focuses more specifically on the spatial patterning of rocks in those same three blocks. A variety of spatial statistics are applied to the large rock provenience data set to ascertain quantitatively whether their distribution in those areas is random or non-random and, if non-random, whether the patterns can be attributed to natural geological processes (also Jayalath et al. 2015).

The next five chapters provide the empirical core of the archaeological data from areas of the site where Folsom remains are concentrated: Blocks A, B, C, $\mathrm{D}$, and F, detailed in chapters 7 through II, respectively. Each chapter provides 
specific information on the types and diversity of stone artifacts, bone, and other recovered materials (daub, opal-CT), along with any hearths or other features in that excavation area; the occurrence of possible architectural elements such as entryways, benches, and storage areas; what the artifacts and organic remains might reveal of the types of activities that took place; and the spatial patterning of remains and their relationship to any architectural features, to ascertain if there are different activity areas, particularly relative to the bounded indoor space of a dark, walled structure or perhaps outdoors.

Given the possibility that Mountaineer represents a long-term occupation that may have involved a reduction in mobility, it has the potential to reveal aspects of Folsom technological organization not often seen. That potential is explored with two classes of stone tools-Folsom fluted projectile points (including preforms) and scrapers-in chapters I2 and I3, respectively. Of particular interest are patterns of lithic raw material in the manufacture of these tools; how (or whether) toolstone influenced their manufacture, use, recycling, and discard during the course of occupation; and what these patterns might reveal of planning or gearing-up strategies. The Mountaineer assemblage was distinctive from the outset, in that the great majority of its artifacts are fashioned of high-quality quartzite, which is locally abundant and readily available in the UGB (Stiger 200I). As such, its more than roo projectile points and preforms do not fit the classic image of Folsom points, which are often made of high-quality chert obtained from distant outcrop sources (Bamforth 2009), as is true even of Folsom sites in the relatively nearby San Luis Valley and Rio Grande headwaters (Jodry 1999a, I999b). Chapter I2 explores in depth Folsom point raw material patterning, morphometrics, and their manufacture, maintenance, breakage, loss, and discard to assess their functional, technological, and stylistic variability and how it might reveal aspects of organization, mobility, and land use.

Finally, in chapter I4, we turn to the faunal assemblage. It is, unfortunately, highly fragmented, limiting the types of analyses that can be carried out. The chapter documents the taphonomic processes, natural and cultural, that have impacted the bones. Despite its condition, the faunal assemblage provides some insight into the prey types exploited by Folsom groups, as well as hints (regrettably, little more) to the possible season(s) Folsom groups occupied the site.

This volume aims to provide the data for answering the questions posed in this chapter and to determine if these spatially separated Folsom concentrations were part of a single or multiple occupations and whether, if contemporaneous, they were functional interdependent and integrated entities-matters

\section{Copyrighted material Not for distribution}


taken up as a whole in chapter 15 . In addition to summarizing and discussing the analyses and conclusions drawn, chapter 15 also situates Mountaineer within the larger Folsom context of the Rocky Mountains and the Great Plains. It is true that Mountaineer is only one site among dozens, but we have begun to see that the Folsom archaeological record indicates a great deal more variability in adaptive behavior than traditional models can account for. Reduced mobility, more generalized subsistence patterns, variability in tool manufacture and use-these factors must be integrated into our models so we have a more robust and accurate view of Folsom lifeways. We hope this volume is a step in that direction.

\section{NOTES}

I. The "W" in "W Mountain" is for the large, whitewashed rock letter W (for Western) located on its northern slope.

2. "Folsom-like" was a catch-all term for fluted and sometimes non-fluted Paleoindian lanceolates that did not fit the Folsom type (Meltzer 2006a).

3. Pitblado (2016:30) subsequently acknowledged that this conclusion was driven in large part by her having restricted her study to Late Paleoindian time.

4. The elevation of the Mountaineer site at 2,625 masl puts it in the hypoxia "zone" but still well below the elevation range that requires long-term adaptive responses (Beall 2014), even granting that the effects of hypoxia can be exacerbated by cold temperatures (Aldenderfer 1998; Kornfeld 2015). 